\title{
Modelagem do carbono estocado no tronco de árvores de Eucalyptus com modelos lineares e rede neural artificial
}

\author{
Cícero Jorge Fonseca Dolácio ${ }^{1 *}$ Rudson Silva Oliveira ${ }^{1}$ Nelson Yoshihiro Nakajima ${ }^{1}$ Dimas Agostinho da \\ Silva $^{1}$ Ângelo Augusto Ebling ${ }^{2}$ Jonas Elias Castro da Rocha ${ }^{3}$
}

${ }^{1}$ Universidade Federal do Paraná, Av. Prefeito Lothário Meissner, 632, Jardim Botânico, Curitiba-PR, 80.210-170

${ }^{2}$ Universidade Federal Rural da Amazônia, Campus de Parauapebas, Rod. PA 275 s/n, km 13, Zona Rural, Parauapebas-PA, 68.515-000

${ }^{3}$ Universidade Federal Rural da Amazônia, Campus de Paragominas, Rod. PA-256, s/n, Nova Conquista, Paragominas-PA, 68.625-970

*Author for correspondence: cicerodolacio@ufpr.br

Received: January 2019/ Accepted: June 2019/ Published: June 2019

\section{Resumo}

Os plantios de Eucalyptus se destacam devido ao seu rápido crescimento e a elevada capacidade em fixar carbono na sua biomassa. Entretanto, os métodos diretos utilizados para quantificar essa variável são onerosos, por isso, esta pesquisa buscou avaliar a eficiência de métodos indiretos ao estimar o estoque de carbono orgânico na madeira e na casca de Eucalyptus, a partir de equações alométricas desenvolvidas por regressão linear e por rede neural artificial (RNA). Este estudo foi conduzido com dados de dez materiais genéticos de Eucalyptus implantados na região sudeste do estado do Pará. Cada material genético foi amostrado com quatro repetições aos dois anos de idade, aleatoriamente, totalizando 40 árvores amostras. Adotamos teores de carbono médio indicado na literatura para determinar a quantidade de carbono e proceder com o desenvolvimento das equações alométricas por regressão linear e por RNA para estimar o carbono estocado em cada componente (madeira e casca). Os resultados apontaram que a quantidade de carbono estocado diferem entre os materiais genéticos, com destaque para o PP-406 que apresentou as maiores médias para madeira $\left(23,55 \mathrm{~kg}_{\text {árv }}{ }^{-1}\right)$ e casca $\left(2,51 \mathrm{~kg}\right.$ áv $^{-}$ $\left.{ }^{1}\right)$. As equações alométricas desenvolvidas por regressão linear estimaram o carbono estocado nos dois componentes com menor precisão, em comparação com as estimativas das RNA. Contudo, somente para as estimativas do carbono estocado na madeira houve precisão satisfatória de ambos os métodos.

Palavras-chave: Aprendizado de máquinas, Modelagem alométrica, Regressão linear, Sequestro de carbono.

\begin{abstract}
The Eucalyptus plantations stand out due to their rapid growth and high capacity to fix carbon in their biomass. However, the direct method used to quantify this variable are costly, therefore, this research sought to evaluate the efficiency of indirect methods when estimating the organic carbon stock in Eucalyptus wood and bark from allometric equations developed by linear regression and artificial neural network (ANN). This study was conducted from ten Eucalyptus genetic materials cultivated in southeast region of Pará state. Each genetic material was sampled with four repetitions at two years old, randomly, totality 40 sample trees. We adopted the average carbon content indicated in the literature to determine the amount of carbon and proceed with the development of the allometric equations by linear regression and ANN to estimate the carbon stock in each component (wood and bark). The results showed that the amount of carbon stocked differs between genetic
\end{abstract}

materials, highlighting the PP-406 that presented the highest averages for wood $\left(23,55 \mathrm{~kg} \mathrm{árv}^{-1}\right)$ and bark $\left(2,51 \mathrm{~kg} \mathrm{árv}^{-1}\right)$. The allometric equations developed by linear regression estimated the carbon stock with less precision in both components compared to ANN estimates. However, only for estimates of the carbon stocked in the wood was there satisfactory accuracy of both methods.

Keywords: Machine learning, Allometric modeling, Linear regression, Carbon sequestration.

\section{Introdução}

O crescimento da demanda por produtos florestais está constantemente promovendo o aprimoramento técnico da ferramenta do manejo aplicado em florestas no Brasil. Neste processo, a quantificação da biomassa é imprescindível para a compreensão do processo de crescimento e alocação de carbono nos diferentes componentes das árvores (Mello e Gonçalves 2008).

Devido a importância das florestas no ciclo do carbono global, tem sido crescente o interesse de muitos pesquisadores sobre a quantificação da biomassa florestal, principalmente pelo potencial de armazenamento do carbono atmosférico nas florestas (Ratuchne et al. 2016). Esse interesse pode ser atribuído ao crescimento das emissões de gases do efeito estufa em todo mundo, porém, a quantificação é bastante trabalhosa e onerosa, o que dificulta a realização de pesquisas.

Espécies do gênero Eucalyptus se destacam na fixação do carbono atmosférico, em função de seu rápido crescimento e elevada produtividade (Soares e Oliveira 2002). Fato que justifica, segundo Caldeira et al. (2015), o crescimento e interesse por estudos sobre a capacidade das florestas plantadas em remover o gás carbônico da atmosfera e armazenar o carbono em sua biomassa. Os resultados desse estudo poderão contribuir com informações sobre o estoque de carbono nos plantios de eucalipto, que podem desempenhar papel fundamental nos projetos relacionados a fixação de carbono na referida região de estudo.

Plantios com espécies do gênero Eucalyptus tem se estendido no Brasil a regiões diferentes das tradicionais (Garlet et al. 2016), sendo necessário estudos para determinar ou prever o potencial produtivo nessas regiões, visando otimizar o uso de recursos da produção florestal (Santana et al. 2008). Embora haja muitos estudos avaliando métodos para quantificar biomassa e carbono em espécies do gênero Eucalyptus nas diferentes regiões do Brasil, o conhecimento sobre o tema na mesorregião sudeste do estado do Pará é incipiente. 
De acordo com Vieira et al. (2008), a quantificação do estoque de carbono pode ser feita por métodos que vão desde a análise destrutiva, com o abate das árvores e coleta de amostras até a análise não destrutiva, que compreende o uso de métodos estimativos, sendo a regressão o método mais utilizado. Uma alternativa ao uso dos métodos tradicionais de predição, é o uso de redes neurais artificiais (Binoti et al. 2013; Haykin 2009).

Atualmente, várias empresas do setor florestal utilizam o método indireto para fazer previsão da quantidade de carbono fixado na árvore. Essa informação dá suporte ao planejamento e tomada de decisão da necessidade ou não de aumento da área reflorestada, bem como para a obtenção de crédito de carbono (Assis et al. 2015), comprovando a importância do método para planejamentos florestais mais eficientes.

Sob a hipótese de que existiam diferenças na quantidade de carbono estocada nos componentes entre os diferentes materiais genéticos avaliados e entre os métodos estimativos, os principais objetivos deste estudo foram quantificar o carbono estocado na biomassa dos componentes madeira e casca; e desenvolver equações alométricas por regressão linear e por rede neural artificial para estimar a quantidade de carbono estocada nos componentes madeira e casca de dez materiais genéticos de Eucalyptus aos dois anos de idade, na Mesorregião Sudeste Paraense.

\section{Material e métodos}

$\mathrm{O}$ estudo foi conduzido em plantios experimentais com diferentes materiais genéticos de Eucalyptus aos dois anos de idade (Tabela 1), localizados no município de Dom Eliseu - PA, mesorregião Sudeste do estado do Pará. O clima do Município, segundo classificação de Köppen é o Awi, clima tropical chuvoso, com expressivo período de estiagem (Sistema de Proteção da Amazônia 2009). A temperatura média anual está em torno de $25^{\circ} \mathrm{C}$ e a precipitação pluviométrica média anual é de 1.638 $\mathrm{mm}$, entretanto, há uma grande variabilidade climática na região, podendo a precipitação anual média variar de 1.445 a $2.030 \mathrm{~mm}$ dentro do município (Hijmans et al. 2005).

Tabela 1 - Materiais genéticos avaliados

\begin{tabular}{lc}
$\begin{array}{l}\text { Material } \\
\text { genético }\end{array}$ & Descrição \\
\hline PP-406 & Eucalyptus urophylla \\
PP-408 & Eucalyptus urophylla \\
PP-432 & Híbrido de polinização aberta \\
PP-435 & Eucalyptus urophylla \\
PP-436 & Eucalyptus urophylla \\
PP-443 & Eucalyptus grandis $\mathrm{x}$ Eucalyptus tereticornis \\
PP-455 & Híbrido de polinização aberta \\
PP-479 & Eucalyptus urophylla $\times$ Eucalyptus grandis \\
PP-490 & Eucalyptus urophylla \\
PP-500 & Híbrido de polinização aberta \\
\hline
\end{tabular}

Os plantios experimentais estão implantados na Fazenda Rio Concrem que pertencente ao Grupo Concrem, localizados entre as coordenadas UTM 880220 L e 9539788 S, DATUM: SIRGAS2000, Zona: 22S. Esses plantios possuem espaçamento de 3 x 2 metros e estão a $260 \mathrm{~m}$ de altitude, com solo classificado como Latossolo Amarelo Distrófico, textura muito argilosa considerando o Sistema Brasileiro de Classificação de Solos (Santos et al. 2013).
Foram amostradas aleatoriamente quatro árvores por material genético, totalizando uma amostra de 40 árvores; e estas foram cortadas o mais próximo possível do solo com auxílio de motosserra, visando o maior aproveitamento de biomassa. A altura total (h) de cada árvore foi obtida com auxílio de uma trena e, em seguida, foram submetidas à cubagem para determinação dos volumes individuais com casca ( $\mathrm{v}_{\mathrm{cc}}$ ), pela fórmula proposta por Smalian, método mais utilizado para determinação de volume (Costa et al. 2016; Hsing et al. 2016), os diâmetros $\left(\mathrm{d}_{\mathrm{cc}}\right)$ foram medidos ao longo do tronco nas alturas 0,$05 ; 0,50 ; 1,00 ; 1,30 ; 2,00 ; 4,00 \mathrm{~m}$; e assim sucessivamente, de $2 \mathrm{em} 2 \mathrm{~m}$, até atingir a altura limitada pela circunferência mínima de $2 \mathrm{~cm}$.

Após a cubagem, as árvores foram segmentadas por componente e a determinação da biomassa verde dos componentes madeira e casca foi feita por método destrutivo. Para tanto, o tronco foi seccionado em toretes de aproximadamente 1,5 metros, para separação da casca e a determinação da biomassa verde dos componentes $\left(m_{v}\right)$ ainda em campo, com auxílio de uma balança digital de gancho com capacidade máxima de $50 \mathrm{~kg}$ e precisão de $0,01 \mathrm{~kg}$.

Com a Equação 1, foi determinada a biomassa seca dos componentes $\left(\mathrm{m}_{\mathrm{s}}\right)$, para tanto, foram retirados dois discos de 5 centímetros de espessura em três pontos de amostragem do tronco, o primeiro a 1,30 metros, o segundo a $50 \%$ da altura total e o terceiro a 2,00 metros da ponta, que tiveram a casca separada para determinação da biomassa por componente. Essas amostras foram pesadas ainda em campo para obtenção da biomassa verde $\left(m_{v a}\right)$ e em seguida foram submetidas à secagem em estufa de circulação forçada com temperatura de 103 ${ }^{\circ} \mathrm{C}$ até atingir umidade inferior a $6 \%$, determinada por medidor de contato portátil, para obtenção da biomassa seca da amostra $\left(\mathrm{m}_{\mathrm{sa}}\right)$.

$$
\mathrm{m}_{\mathrm{s}}=\left(\mathrm{m}_{\mathrm{sa}} / \mathrm{m}_{\mathrm{va}}\right) \mathrm{m}_{\mathrm{v}}
$$

Em que, $\mathrm{m}_{\mathrm{s}}$ é a biomassa seca total do componente, em $\mathrm{kg}$; msa é a biomassa seca da amostra, em $\mathrm{kg}$; mva é a biomassa verde da amostra, em $\mathrm{kg}$; e $\mathrm{m}_{\mathrm{v}}$ é a biomassa verde total do componente, em $\mathrm{kg}$.

Considerando que o uso de um teor médio de $50 \%$ para determinar a quantidade de carbono estocada na biomassa florestal poderia acarretar em erro de superestimativa no estoque de carbono total, pois em diversos trabalhos não foi encontrado esse teor médio (Dallagnol et al. 2011; Ribeiro et al. 2015), a estimativa do carbono estocado nos componentes foi obtida pelo produto entre a quantidade de biomassa seca dos componentes e os teores de carbono $46,56 \%$ e $43,71 \%$ para os componentes madeira e casca, respectivamente, obtidos por Silva et al. (2015), em plantios clonais de Eucalyptus spp., com idade de 2,3 anos, sob regimes de manejos silviculturais de alto fuste e em espaçamento médio de 3,0 x 2,0 m.

Para analisar possíveis diferenças nas quantidades de carbono estocadas nos componentes entre os materiais genéticos, efetuou-se primeiramente a verificação da homogeneidade de variância pelo teste de Bartlett (1937), identificadas variâncias homogêneas, procedeu-se com a análise de variância seguindo o delineamento inteiramente casualizado, e quando verificada significância ( $\left.p_{\text {value }}<0,05\right)$ com base no valor de Fisher, as médias foram comparadas pelo teste de Tukey ao nível 
de 5\% de significância, utilizando o software R versão 3.4.4 (R Core Team, 2018).

Equações alométricas foram desenvolvidas por meio do ajuste de modelos alométricos por regressão linear e pelo treinamento de redes neurais artificiais (RNA) para estimar o carbono estocado na biomassa seca dos componentes de árvores de eucalipto. Para tanto, os dados coletados foram divididos aleatoriamente em conjunto de ajuste ou treinamento, composto por $75 \%$ do total dos dados, e de validação, correspondendo aos dados complementares (25\%).

Nos modelos alométricos ajustados (Tabela 2), a quantidade de carbono estocada nos componentes foi utilizada como variável dependente e como variáveis independentes foram testados o diâmetro com casca medido a 1,3 m do nível do solo (dap $\mathrm{cc}$ ), em centímetros, a altura total (h), em metros, e suas variações e combinações.

Tabela 2 - Modelos alométricos ajustados para estimar o carbono estocado nos componentes dos materiais genéticos avaliados

\begin{tabular}{|c|c|c|}
\hline$\overline{\mathbf{N}}$ & Modelo & Autor \\
\hline$\overline{1}$ & $\operatorname{Ln} \widehat{Y}=\beta_{0}+\beta_{1} \operatorname{Ln}\left(\operatorname{dap}_{\mathrm{cc}}\right)+\varepsilon_{\mathrm{i}}$ & Husch \\
\hline 2 & $\widehat{\mathrm{Y}}=\beta_{0}+\beta_{1}\left(\operatorname{dap}_{\mathrm{cc}}^{2} \mathrm{~h}\right)+\varepsilon_{\mathrm{i}}$ & Spurr \\
\hline 3 & $\operatorname{Ln} \widehat{Y}=\beta_{0}+\beta_{1} \operatorname{Ln}\left(\operatorname{dap}_{\mathrm{cc}}^{2} \mathrm{~h}\right)+\varepsilon_{\mathrm{i}}$ & Spurr Logarítimico \\
\hline 4 & $\operatorname{Ln} \widehat{Y}=\beta_{0}+\beta_{1} \operatorname{Ln}\left(\right.$ dap $\left._{c c}\right)+\beta_{2} \operatorname{Ln}(h)+\varepsilon_{i}$ & Schumacher e Hall \\
\hline
\end{tabular}

Foram treinadas redes neurais artificiais do tipo perceptron de múltiplas camadas (MLP), composta por uma camada de entrada, uma camada intermediária e uma camada de saída, com uso do algoritmo de retropropagação do erro para treinamento do tipo supervisionado, pois as variáveis de entrada e saída foram fornecidas à rede para definição dos pesos e dos bias.

Na camada de entrada foram utilizados 12 neurônios, referentes as variáveis quantitativas contínuas: dap cc $_{c}$, em centímetros, e h, em metros; e aos materiais genéticos, como variáveis categóricas. Em resumo, dois neurônios representaram as variáveis quantitativas contínuas e dez neurônios as variáveis categóricas. Foram testados de 2 a 30 neurônios na camada intermediária com o uso das funções de ativação tangente hiperbólica e logística nesta camada. Na camada de saída foi utilizado apenas um neurônio que correspondeu a quantidade de carbono estocada na biomassa seca dos componentes avaliados. Por isso, foram avaliadas 58 configurações diferentes de redes neurais artificiais para cada componente, correspondentes a todas as combinações possíveis do número de neurônios na camada intermediária e funções de ativação.

$\mathrm{O}$ ajuste dos modelos alométricos por regressão linear e suas validações foram realizados no software $\mathrm{R}$ versão 3.4.4 e o treinamento das redes neurais artificiais foram feitas com o pacote "neuralnet" (Fritsch e Guenther 2016).

Para avaliar a precisão dos modelos alométricos após ajuste, o coeficiente de determinação ajustado $\left(\mathrm{R}^{2}{ }_{\text {aj. }}\right)$, erro padrão da estimativa percentual $\left(\mathrm{S}_{\mathrm{yx}}\right)$ e desvio médio percentual (DMP) foram utilizados como medida de precisão, além da análise gráfica dos resíduos padronizados. As medidas de precisão dos modelos ajustados na forma logarítmica foram calculadas após correção dos erros sistemáticos, com o uso do Fator de Correção de Meyer.
Dentre as 58 redes treinadas, foram selecionadas apenas as quatro melhores, com base no maior coeficiente de correlação linear de Pearson $\left(\mathrm{r}_{\mathrm{yy}} \hat{)}\right)$ entre os valores observados e estimados. Após esta seleção, a precisão das quatro redes foi avaliada pelo ryŷ, desvio médio percentual (DMP) e raiz do erro quadrático médio (REQM), em percentagem, bem como, pela análise gráfica dos resíduos padronizados.

Para a validação dos modelos alométricos após ajuste e das melhores RNA treinadas, assim como, para comparação dos métodos, foram utilizados o $r_{y y} \hat{~ e ~ a ~}$ REQM, bem como o teste Qui-quadrado $\left(\square^{2}\right)$ ao nível de $5 \%$ de significância. Somente a melhor equação alométrica e a melhor RNA foram analisadas pela dispersão gráfica dos resíduos padronizados e pelo gráfico de valores observados por estimados. A validação serve para garantir se a equação e a rede treinada, podem ser aplicadas em conjunto de dados diferentes dos utilizados no processo inicial, porém, que apresentem a mesma amplitude de dap cc $\mathrm{e} h$, além das mesmas condições fisioedafoclimáticas do sítio e materiais genéticos.

\section{Resultados e discussão}

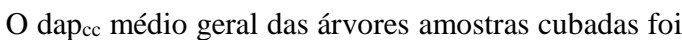
igual a 12,64 cm (Tabela 3), com medidas que variam de $11,16 \mathrm{~cm}(\mathrm{PP}-432)$ a 13,97 cm (PP-408) e os valores de $\mathrm{h}$ e $v_{c c}$ apresentaram média geral igual a $15,62 \mathrm{~m} \mathrm{e}$ $0,092665 \mathrm{~m}^{3}$, ainda, essas variáveis apresentaram $\mathrm{CV}$ iguais a $3,34 \%$ e $11,88 \%$, respectivamente.

Tabela 3 - Valores descritivos (média \pm desvio padrão) das variáveis dendrométricas dos materiais genéticos avaliados

\begin{tabular}{lccc}
$\begin{array}{l}\text { Material } \\
\text { genético }\end{array}$ & $\begin{array}{c}\mathbf{d a p}_{\mathbf{c c}} \\
(\mathbf{c m})\end{array}$ & $\begin{array}{c}\mathbf{h} \\
(\mathbf{m})\end{array}$ & $\begin{array}{c}\mathbf{v}_{\mathbf{c c}} \\
\left(\mathbf{m}^{3}\right)\end{array}$ \\
\hline PP-406 & $12,57 \pm 0,79$ & $16,37 \pm 0,94$ & $0,099136 \pm 0,014021$ \\
PP-408 & $13,97 \pm 0,79$ & $16,88 \pm 0,50$ & $0,121022 \pm 0,010044$ \\
PP-432 & $11,16 \pm 0,76$ & $14,04 \pm 0,31$ & $0,070388 \pm 0,007983$ \\
PP-435 & $12,73 \pm 0,83$ & $16,41 \pm 0,10$ & $0,095658 \pm 0,014155$ \\
PP-436 & $13,28 \pm 0,85$ & $16,15 \pm 0,55$ & $0,098008 \pm 0,015440$ \\
PP-443 & $13,51 \pm 1,06$ & $15,77 \pm 0,41$ & $0,100915 \pm 0,015058$ \\
PP-455 & $12,73 \pm 0,15$ & $16,32 \pm 1,28$ & $0,100041 \pm 0,010225$ \\
PP-479 & $12,37 \pm 0,59$ & $14,01 \pm 0,54$ & $0,082188 \pm 0,009080$ \\
PP-490 & $12,14 \pm 0,47$ & $14,33 \pm 0,28$ & $0,079683 \pm 0,005096$ \\
PP-500 & $11,91 \pm 0,54$ & $15,94 \pm 0,42$ & $0,079607 \pm 0,007129$ \\
\hline Média Geral & $12,64 \pm 1,01$ & $15,62 \pm 1,17$ & $0,092665 \pm 0,017302$ \\
CV(\%) & 5,45 & 3,34 & 11,88
\end{tabular}

dap cc: diâmetro medido a 1,3 $\mathrm{m}$ do nível do solo, em $\mathrm{cm}$; h: altura total, em m; $v_{c c}$ : volume individual com casca, em $\mathrm{m}^{3}$; e CV(\%): coeficiente de variação, em percentagem.

Os valores de dap cc $_{\text {e de }} \mathrm{h}$ das árvores desse estudo são muito superiores aos encontrados por Viera et al. (2012), que avaliaram a espécie Eucalyptus grandis com 18 meses de idade e espaçamento de $3 \times 2,25 \mathrm{~m}$, pouco maior ao deste trabalho, e obtiveram valores médios de dap $_{\mathrm{cc}}$ e h iguais a $6,7 \mathrm{~cm} \mathrm{e} 7,0 \mathrm{~m}$, respectivamente.

Os diferentes componentes avaliados apresentaram variâncias individuais dos tratamentos homogêneas, não requerendo transformação dos dados, e as análises de variâncias mostraram que há, entre as médias de carbono orgânico estocado na biomassa da casca e da madeira pelos diferentes materiais genéticos, pelo menos uma que se diferencia estatisticamente dos demais.

O material genético PP-406 estocou a maior quantidade de carbono no componente casca $(2,51 \mathrm{~kg})$, 
mas esta foi, estatisticamente, igual as dos materiais genéticos que apresentaram a segunda e a terceira maior quantidade estocada; e ao avaliar a quantidade de carbono estocada na biomassa da madeira, notou-se que a maior quantidade estocada pelo material genético PP-406 foi, estatisticamente, igual a quantidade do PP-408, segundo que mais estocou carbono, e que se diferiu dos materiais genéticos que estocaram carbono com quantidade igual ou inferior a 14,82 kg (Tabela 4).

Tabela 4 - Comparação das médias de carbono estocado nos componentes dos materiais genéticos avaliados

\begin{tabular}{|c|c|c|}
\hline \multirow{2}{*}{$\begin{array}{l}\text { Material } \\
\text { genético }\end{array}$} & \multicolumn{2}{|c|}{ Carbono (kg) } \\
\hline & Casca & Madeira \\
\hline PP-406 & $2,51 \pm 0,42 \mathrm{a}$ & $23,55 \pm 3,71$ a \\
\hline PP-408 & $1,60 \pm 0,11 \mathrm{c}$ & $20,87 \pm 1,80 \mathrm{ab}$ \\
\hline PP-432 & $1,07 \pm 0,16 \mathrm{~d}$ & $11,68 \pm 1,25 \mathrm{~d}$ \\
\hline PP-435 & $2,41 \pm 0,40 \mathrm{ab}$ & $16,92 \pm 2,63 \mathrm{bc}$ \\
\hline PP-436 & $1,85 \pm 0,28 a b c$ & $14,82 \pm 2,76 \mathrm{~cd}$ \\
\hline PP-443 & $1,76 \pm 0,27 \mathrm{bc}$ & $17,00 \pm 2,67 \mathrm{bc}$ \\
\hline PP-455 & $1,47 \pm 0,25 \mathrm{~cd}$ & $16,83 \pm 1,25 \mathrm{bc}$ \\
\hline PP-479 & $1,08 \pm 0,14 \mathrm{~d}$ & $13,88 \pm 1,49 \mathrm{~cd}$ \\
\hline PP-490 & $1,48 \pm 0,21 \mathrm{~cd}$ & $14,52 \pm 1,47 \mathrm{~cd}$ \\
\hline PP-500 & $1,46 \pm 0,11 \mathrm{~cd}$ & $13,00 \pm 1,47 \mathrm{~cd}$ \\
\hline F & $15,5^{*}$ & $11,0^{*}$ \\
\hline K & $10,38^{\text {ns }}$ & $7,49^{\text {ns }}$ \\
\hline
\end{tabular}

Gatto et al. (2011) estimaram o estoque de carbono orgânico em plantações de eucalipto na região centroleste do estado de Minas Gerais com 24 meses de idade, sob espaçamento de $3 \mathrm{~m} \times 2 \mathrm{~m}$, e encontraram valores de carbono orgânico estocado na casca que variaram de 0,98 a 2,51 $\mathrm{Mg} \mathrm{ha} \mathrm{ha}^{-1}$, nos piores e melhores sítios, respectivamente. Convertendo esses valores para unidades de árvore têm-se, respectivamente, valores iguais a 0,59 e $1,51 \mathrm{~kg}^{2}$ árvore ${ }^{-1}$, portanto, inferiores ao máximo encontrado nesse estudo. Já para a madeira, aos 5,5 anos, Ribeiro et al. (2015) encontraram, em plantação com material genético do hibrido Eucalyptus urophylla $\mathrm{x}$ E. grandis, quantidade média de carbono igual a 40,84 $\mathrm{kg}$.

A partir da análise dos ajustes dos modelos alométricos (Tabela 5), verificou-se que as equações ajustadas para estimar o carbono da casca não apresentaram bom ajuste aos dados observados, pois o $\mathrm{R}^{2}{ }_{\text {aj. }}$ apresentou um poder explicativo do comportamento da variável resposta entre 0,278 e 0,375 e o $S_{\mathrm{yx}}$ variou de $28,20 \%$ a $26,24 \%$, correspondendo respectivamente, as equações que apresentaram pior e melhor estimativas no processo de ajuste. A falta de um bom ajuste pode ser atribuída a possibilidade de haver efeitos específicos de cada material genético na quantidade de carbono estocada neste componente, indicando que utilizar somente o dap $\mathrm{cc}$ e a h, como variáveis independentes, para desenvolver equações alométricas genéricas a nível de local não é o suficiente para que haja boa precisão, por isso, ajustar uma equação por material genético poderia solucionar esta problemática.
Tabela 5 - Coeficientes dos modelos alométricos ajustados e medidas que avaliam a precisão para estimar o carbono estocado nos componentes

\begin{tabular}{|c|c|c|c|c|c|}
\hline $\mathbf{N}$ & Coeficiente & FCM & $\mathbf{R}_{\text {aj. }}^{2}$ & $S_{y x}(\%)$ & DMP (\%) \\
\hline \multicolumn{6}{|c|}{ Casca } \\
\hline 2 & $\begin{array}{cc}\beta_{0} & -0,163163 \\
\beta_{1} & 0,000743\end{array}$ & - & 0,375 & 26,24 & 5,26 \\
\hline 3 & $\begin{array}{cc}\beta_{0} & -8,381695 \\
\beta_{1} & 1,134968\end{array}$ & 1,026718 & 0,371 & 26,31 & 5,14 \\
\hline 4 & $\begin{array}{lc}\beta_{0} & -8,536073 \\
\beta_{1} & 1,266681 \\
\beta_{2} & 2,116170\end{array}$ & 1,025756 & 0,369 & 26,36 & 4,87 \\
\hline 1 & $\begin{array}{cc}\beta_{0} & -6,740103 \\
\beta_{1} & 2,851856 \\
\end{array}$ & 1,032860 & 0,278 & 28,20 & 6,35 \\
\hline \multicolumn{6}{|c|}{ Madeira } \\
\hline 2 & $\begin{array}{lc}\beta_{0} & -0,324612 \\
\beta_{1} & 0,006659 \\
\end{array}$ & - & 0,559 & 17,03 & 2,03 \\
\hline 3 & $\begin{array}{cc}\beta_{0} & -4,935006 \\
\beta_{1} & 0,986213 \\
\end{array}$ & 1,010850 & 0,558 & 17,04 & 2,08 \\
\hline 4 & $\begin{array}{lc}\beta_{0} & -4,962628 \\
\beta_{1} & 1,792916 \\
\beta_{2} & 1,161778\end{array}$ & 1,011192 & 0,552 & 17,17 & 2,11 \\
\hline 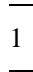 & $\begin{array}{cc}\beta_{0} & -3,976640 \\
\beta_{1} & 2,663177 \\
\end{array}$ & 1,013172 & 0,446 & 19,09 & 2,50 \\
\hline
\end{tabular}

$\beta_{0}, \beta_{1}$ e $\beta_{2}$ : coeficientes ajustados; FCM: fator de correção de Meyer; $\mathrm{R}_{\text {aj.: }}^{2}$ coeficiente de determinação ajustado; $\mathrm{S}_{\mathrm{yx}}(\%)$ : erro padrão da estimativa, em percentagem; e DMP (\%): desvio médio, em percentagem.

As equações desenvolvidas para estimar carbono estocado na madeira apresentaram $\mathrm{R}^{2}$ aj. entre $0,446 \mathrm{e}$ 0,559 , indicando que as variáveis utilizadas como independentes, melhor se correlacionam para este componente e o $S_{\mathrm{yx}}$ ficou entre $17,03 \%$ e 19,09 . O DMP, utilizado para verificar em termos médios se os valores estimados apresentaram tendenciosidade, indicou tendência de superestimação do carbono estocado nos dois componentes, contudo, esta foi menor ao considerar $\mathrm{o}$ ajuste à madeira.

Saidelles et al. (2009) ajustaram modelo que utiliza somente o dap cc $_{\mathrm{c}}$ como variável independente para estimar o estoque de carbono orgânico contido na casca das árvores de Acacia mearnsii com quatro anos de idade e obtiveram bom ajuste, expresso pelo valor de 0,97 para o coeficiente de determinação $\left(\mathrm{R}^{2}\right)$ e pelo baixo $\mathrm{S}_{\mathrm{yx}}(1,5 \%)$. Também, ao estimarem o estoque de carbono na madeira de árvores de Eucalyptus grandis, Soares et al. (2005) ajustaram o modelo linearizado de Schumacher e Hall (N 4) e encontraram valores de 0,98 e $1,14 \mathrm{~kg}$, para as $\mathrm{R}^{2}$ e $\mathrm{S}_{\mathrm{yx}}$, respectivamente.

A análise gráfica dos resíduos padronizados (Figura 1) demonstra porque os modelos ajustados para estimar o carbono estocado na casa não apresentaram boas medidas de precisão, com notória ausência de homogeneidade na distribuição, a julgar pela subestimativa quando os valores observados estão abaixo de $1,7 \quad \mathrm{~kg} \quad \mathrm{e}$ superestimativa quando superior a $1,7 \mathrm{~kg}$, comprovando os baixos valores de ajuste.

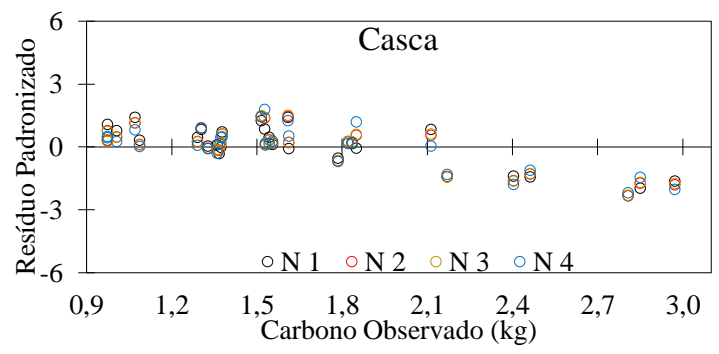




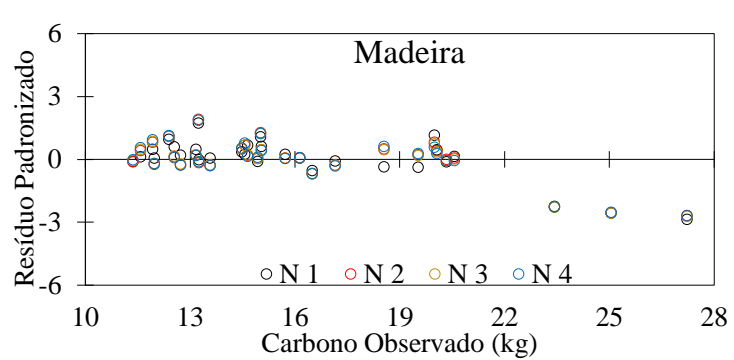

Figura 1 - Gráficos de dispersão dos resíduos padronizados dos modelos alométricos ajustados para estimar o carbono estocado nos componentes

A dispersão para estimativas do carbono estocado na madeira revela tendência em superestimar quando os valores reais são menores que $20 \mathrm{~kg}$ e de subestimar quando acima. Mesmo que as medidas de precisão para a madeira tenham sido melhores que as medidas para estimativa da casca, nenhum dos ajustes apresentaram outliers, haja vista a ausência de valores acima de três desvios. A maior amplitude dos resíduos foi observada nas estimativas para a madeira, pela equação 7 que varia de $-2,73$ a 1,86 e indica que esta foi a menos exata entre todas as estimativas.

No geral, as redes treinadas apresentaram bom desempenho na estimativa do carbono para todos os componentes. As redes selecionadas para estimativa da casca, apresentaram $\mathrm{r}_{\mathrm{yyy}}$ superiores a 0,99 (Tabela 7 ), com destaque à rede 1 , pois seu valor ficou muito próximo de um, máximo possível. Os DMP das redes 1, 2 e 3 apresentaram tendência de subestimação e o da rede 4 de superestimação dos valores de saída, os valores da REQM corroboram com os baixos valores desses desvios, pois estão bem próximos de zero e mostram estimativas precisas.

Tabela 7 - Características e medidas que avaliam a precisão das melhores RNA selecionadas para estimar o carbono estocado nos componentes

\begin{tabular}{|c|c|c|c|c|c|c|}
\hline \multirow{2}{*}{\multicolumn{2}{|c|}{ N Arquitetura }} & \multicolumn{2}{|c|}{ Função de Ativação } & \multirow{2}{*}{$\mathbf{r}_{\mathbf{y y}} \hat{\mathbf{y}}$} & \multirow{2}{*}{$\begin{array}{c}\text { DMP } \\
(\%)\end{array}$} & \multirow{2}{*}{$\begin{array}{c}\text { REQM } \\
(\%)\end{array}$} \\
\hline & & C.I. & C.S. & & & \\
\hline \multicolumn{7}{|c|}{ Casca } \\
\hline 1 & $12-28-1$ & Tangente & Tangente & 0,9999 & $-0,05$ & 0,5829 \\
\hline 2 & $12-6-1$ & Tangente & Tangente & 0,9978 & $-0,06$ & 2,1922 \\
\hline 3 & $12-27-1$ & Tangente & Tangente & 0,9995 & $-0,07$ & 1,0986 \\
\hline 4 & $12-26-1$ & Tangente & Logística & 0,9992 & 0,07 & 1,3866 \\
\hline \multicolumn{7}{|c|}{ Madeira } \\
\hline 1 & $12-29-1$ & Tangente & Tangente & 0,9997 & $-0,04$ & 0,6517 \\
\hline 2 & $12-26-1$ & Tangente & Tangente & 0,9997 & $-0,04$ & 0,6212 \\
\hline 3 & $12-22-1$ & Tangente & Tangente & 0,9998 & $3-0,04$ & 0,5711 \\
\hline 4 & $12-7-1$ & Tangente & Tangente & 0,9997 & $-0,04$ & 0,6074 \\
\hline
\end{tabular}

Altos valores de $\mathrm{r}_{\mathrm{yy}} \hat{\mathrm{t}}$ também foram encontrados ao treinar as redes para estimar o carbono estocado na madeira, pois estão todos acima de 0,999 . Todas as redes apresentaram valores negativos de DMP, indicando subestimação e a precisão medida pela REQM comprova que as estimativas geradas são muito precisas, pois todos valores estão abaixo de $0,7 \%$. A representação gráfica (Figura 2) comprova os ótimos valores das medidas de precisão utilizadas para avaliar as redes.
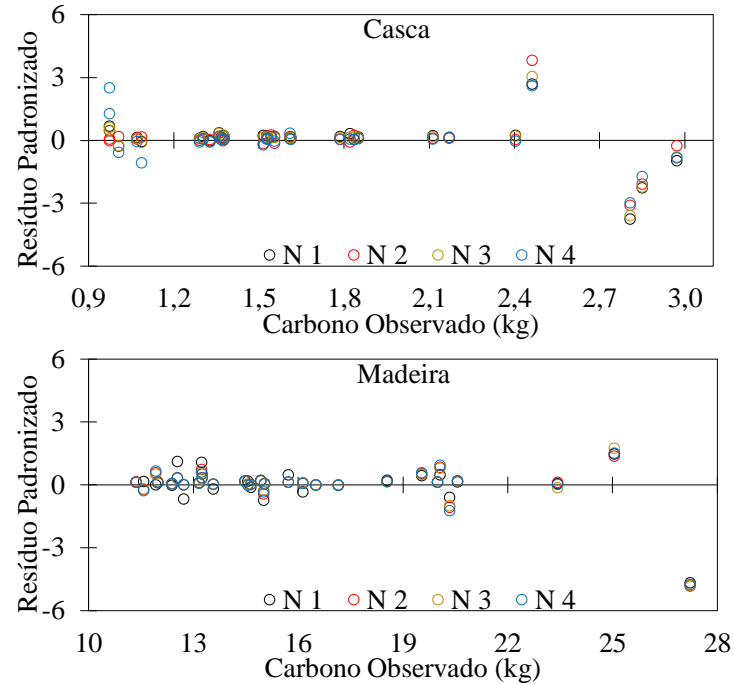

Figura 2 - Gráficos de dispersão dos resíduos padronizados das melhores RNA selecionadas para estimar o carbono estocado nos componentes

Com exceção de rede 4, as demais apresentaram pelo menos uma estimativa para o carbono estocado na casca que pode ser considerada outlier, entretanto a distribuição desta rede para os menores valores observados foi menos homogênea. Ao avaliar a homogeneidade na distribuição dos resíduos para estimativa do carbono estocado na madeira, percebe-se a presença de apenas um outlier para as estimativas das redes, que tendeu a subestimar para o maior valor observado.

A validação foi utilizada para verificar a confiabilidade das estimativas das equações ajustadas e das redes treinadas quando comparadas aos valores reais, para tanto, as medidas de precisão calculadas com unidades amostrais separadas aleatoriamente estão apresentadas na Tabela 8 .

Tabela 8 - Medidas de precisão dos dois métodos para validação da estimativa do carbono estocado nos componentes

\begin{tabular}{|c|c|c|c|c|c|c|}
\hline \multirow[b]{2}{*}{$\mathbf{N}$} & \multicolumn{3}{|c|}{ Regressão } & \multicolumn{3}{|c|}{ RNA } \\
\hline & $\mathbf{r}_{\mathbf{y y}}$ & $\begin{array}{c}\text { REQM } \\
(\%)\end{array}$ & $\chi^{2}$ & $\mathbf{r}_{\mathbf{y y}}$ & $\begin{array}{c}\text { REQM } \\
(\%)\end{array}$ & $\chi^{2}$ \\
\hline & \multicolumn{6}{|c|}{ Casca } \\
\hline 1 & 0,48931 & 32,15 & $1,390^{\mathrm{ns}}$ & 0,85320 & 21,51 & $0,443^{\text {ns }}$ \\
\hline 2 & 0,54765 & 28,22 & $1,111^{\mathrm{ns}}$ & 0,88721 & 26,14 & $0,714^{\mathrm{ns}}$ \\
\hline 3 & 0,54387 & 29,32 & $1,177^{\mathrm{ns}}$ & 0,85787 & 21,40 & $0,438^{\mathrm{ns}}$ \\
\hline 4 & 0,59749 & 23,19 & $0,792^{\mathrm{ns}}$ & 0,90643 & 24,41 & $0,641^{\mathrm{ns}}$ \\
\hline & \multicolumn{6}{|c|}{ Madeira } \\
\hline 1 & 0,81673 & 18,10 & $5,361^{\mathrm{ns}}$ & 0,46132 & 20,25 & $8,091^{\mathrm{ns}}$ \\
\hline 2 & 0,83023 & 15,74 & $4,206^{\mathrm{ns}}$ & 0,83607 & 12,91 & $3,189^{\mathrm{ns}}$ \\
\hline 3 & 0,83018 & 15,09 & $3,903^{\mathrm{ns}}$ & 0,79459 & 14,84 & $4,621^{\mathrm{ns}}$ \\
\hline 4 & 0,83025 & 14,33 & $3,563^{\mathrm{ns}}$ & 0,74915 & 16,67 & $6,528^{\mathrm{ns}}$ \\
\hline
\end{tabular}

A validação das equações para o componente casca mostrou que a equação 4 generalizou com maior precisão, pois apresentou maior $r_{y y}$ e menor REQM, ainda, a validação para este componente pela RNA, indicou que a rede 3 gerou as melhores estimativas a dados não utilizados no treinamento, pois apresentou a menor REQM e um alto $r_{y y}$. Já na validação para o 
componente madeira, verificou-se que a equação 4 e a rede 2 apresentaram melhores medidas de precisão.

Apesar de apresentarem distribuições residuais semelhantes para a estimativa do carbono estocado na casca, foi possível observar no gráfico de valores observados por estimados que a RNA 3 estimou com maior precisão quando comparada com as estimativas da equação 4 (Figura 3). Uma desvantagem observada nesta rede foi a baixa precisão quando a quantidade de carbono orgânico fixado na casca apresentou-se com $1,93 \mathrm{~kg}$, contudo isto não pode ser considerado um outlier por não apresentar mais que três desvios.
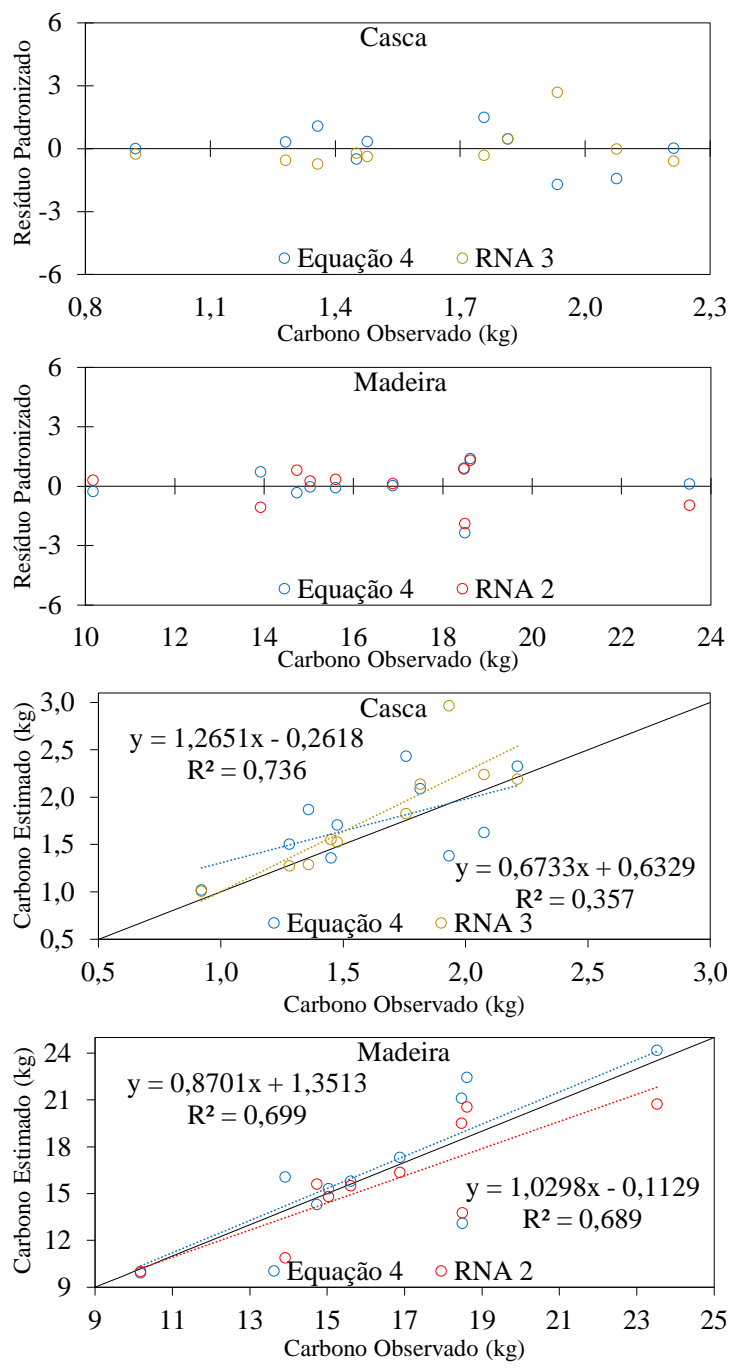

Figura 3 - Gráficos de dispersão dos resíduos padronizados e de valores observados por estimados da melhor equação e da melhor RNA

Corroborando com a semelhança das medidas de precisão da validação, percebe-se distribuição semelhante dos resíduos ao longo do eixo zero para a equação 4 e a RNA 2, quando avaliada a estimativa do carbono estocado na madeira, além da semelhança entre os $\mathrm{R}^{2}$ plotados no gráfico de valores observados por estimados. Isto demonstra adaptabilidade de ambos os métodos à estimativa do carbono estocado na madeira, todavia a RNA apresenta aproximadamente 2\% de REQM a menos que a equação.

De acordo com Leal et al. (2015), a superioridade das RNA com relação aos modelos de regressão, é na maioria das vezes devido a fatores de estrutura e distribuição paralela e a habilidade de generalizar. Em função disso, as RNA resolvem problemas mais complexos, conseguindo modelar várias variáveis, mesmo que haja relações não lineares (Haykin 2009). Isso pode justificar a sua utilização em substituição aos métodos tradicionais de regressão (Castro et al. 2013). Outras vantagens são a não necessidade de normalidade e linearidade dos dados (Egrioglu et al. 2014), pressupostos estatísticos básicos para análises paramétricas, como a regressão que ajusta os coeficientes por mínimos quadrados ordinários, podendo haver também, independência das variáveis estudadas (Santos et al. 2005).

\section{Conclusão}

Corroborando com a hipótese levantada, existem diferenças entre os materiais genéticos quando comparadas as quantidades de carbono estocadas nos componentes. Individualmente, o material genético PP406 destaca-se por apresentar, quantitativamente, as maiores médias de carbono estocado nos dois componentes avaliados.

Os modelos alométricos quando ajustados para estimar o estoque de carbono na casca, não geraram resultados satisfatório como os das RNA que, de maneira geral, apresentam medidas de precisão melhores; e estes métodos apresentaram estimativas do estoque de carbono na madeira com precisões satisfatórias ao serem validados, mas houve superioridade da RNA.

\section{Agradecimentos}

Ao grupo Concrem, em especial à Concrem Wood, pelo subsídio e pelo fomento da pesquisa em suas áreas experimentais.

\section{Referências}

Assis MR, Trugilho PF, Rosado SCS, Protásio TP, Goulart SL (2015) Modelagem da biomassa e do estoque de carbono em plantas jovens de Eucalyptus. Scientia Forestalis, 43(105): 225-233.

Bartlett MS (1937) Properties of sufficiency and statistical tests. Proceedings of the Royal Society of London, 160(901): 268-282. doi: 10.1098/rspa.1937.0109

Binoti MLMS, Binoti DHB, Leite HG (2013) Aplicação de redes neurais artificiais para estimação da altura de povoamentos equiâneos de eucalipto. Revista Árvore, 37(4): 639-645. doi: 10.1590/S010067622013000400007

Caldeira MVW, Watzlawick LF, Viera M, Balbinot R, Castro KC (2015) Biomassa e carbono orgânico em povoamentos de Araucaria angustifolia (Bertol.) Kuntze. Ciência Florestal, 25(4): 1027-1034. doi: $10.5902 / 1980509820664$

Castro RVO, Soares CPB, Martins FB, Leite HG (2013) Crescimento e produção de plantios comerciais de eucalipto estimados por duas categorias de modelos. Pesquisa Agropecuária Brasileira, 48(3): 287-295. doi: 10.1590/S0100-204X2013000300007

Costa EA, Finger CAG, Schneider PR, Hess AF (2016) Função de afilamento e sortimentos de madeira para Araucaria angustifólia. Ciência Florestal, 26(2): 523533. doi: 10.5902/1980509822753

Dallagnol FS, Mognon F, Sanquetta CR, Corte APD (2011) Teores de carbono de cinco espécies florestais e 
seus compartimentos. Floresta e Ambiente, 18(4): 410416. doi: $10.4322 /$ floram. 2011.060

Egrioglu E, Yolcu U, Aladag CH, Bas E (2014) Recurrent multiplicative neuron model artificial neural network for non-linear time series forecasting. Procedia Social and Behavioral Sciences, 109: 1094-1100. doi: 10.1016/j.sbspro.2013.12.593

Fritsch S, Guenther F (2016) Neuralnet: training of neural networks. R package version 1.33. Available from: https://CRAN.R-project.org/package=neuralnet.

Garlet J, Costa EC, Boscardin J (2016) Levantamento da entomofauna em plantios de Eucalyptus spp. por meio de armadilha luminosa em São Francisco de Assis - RS. Ciência Florestal, 26(2): 365-374. doi: 10.5902/1980509822737

Gatto A, Barros NF, Novais IR, Leite HG, Villani EMA (2011) Estoque de carbono na biomassa de plantações de eucalipto na região centro-leste do estado de Minas Gerais. Revista Árvore, 35(4): 895-905. doi: 10.1590/S0100-67622011000500015

Haykin S (2009) Neural networks and learning machines. $3^{\text {rd }}$ Edition. New Jersey: Pearson Prentice Hall. 937p.

Hijmans JR, Cameron SE, Parra JL, Jones PG, Jarvis A (2005) Very high resolution interpolated climate surfaces for global land areas. International journal of climatology, 25: 1965-1978. doi: 10.1002/joc.1276

Hsing TY, Paula NF, Paula RC (2016) Características dendrométricas, químicas e densidade básica da madeira de híbridos de Eucalyptus grandis $\mathrm{x}$ Eucalyptus urophylla. Ciência Florestal, 26(1): 273-283. doi: 10.5902/1980509821119

Leal FA, Miguel EP, Matricardi EAT, Pereira RS (2015) Redes neurais artificiais na estimativa de volume em um plantio de eucalipto em função de fotografias hemisféricas e número de árvores. Revista Brasileira de Biometria, 33(2): 233-249.

Mello SLM, Gonçalves JLM (2008) Equações para estimar a biomassa da parte aérea e do sistema radicular em povoamentos de Eucalyptus grandis em sítios com produtividades distintas. Revista Árvore, 32(1): 101-111. doi: 10.1590/S0100-67622008000100012

R Core Team (2018) R: A language and environment for statistical computing. Vienna, Austria: R Foundation for Statistical Computing. Available from: https://www.Rproject.org.

Ratuchne LC, Koehler HS, Watzlawick LF, Sanquetta CR, Schamne PA (2016) Estado da arte na quantificação de biomassa em raízes de formações florestais. Floresta e Ambiente, 23(3): 450-462. doi: 10.1590/21798087.131515

Ribeiro SC, Soares CPB, Fehrmann L, Jacovine LAG, Gadow KV (2015) Aboveground and belowground biomass and carbon estimates for clonal Eucalyptus trees in Southeast Brazil. Revista Árvore, 39(2): 353-363. doi: 10.1590/0100-67622015000200015

Saidelles FLF, Caldeira MVW, Schumacher MV, Balbinot R (2009) Uso de equações para estimar carbono orgânico em plantações de Acacia mearnsii de Wild. no
Rio Grande do Sul - Brasil. Revista Árvore, 33(5): $907-$ 915. doi: 10.1590/S0100-67622009000500013

Santana RC, Barros NF, Leite HG, Comerford NB, Novais RF (2008) Estimativa de biomassa de plantios de eucalipto no Brasil. Revista Árvore, 32(4): 697-706. doi: 10.1590/S0100-67622008000400011

Santos AM, Seixas JM, Pereira BB, Medronho RA (2005) Usando redes neurais artificiais e regressão logística na predição da hepatite A. Revista Brasileira de Epidemiologia, 8(2): 117-126. doi: 10.1590/S1415790X2005000200004

Santos HG, Jacomine PKT, Anjos LHC, Oliveira VA, Lumbreras JF, Coelho MR, Almeida JA, Cunha TJF, Oliveira JB (2013) Sistema brasileiro de classificação de solos. $3^{\text {rd }}$ Edition. Brasília: Embrapa. 353 p.

Silva CA, Klauberg C, Carvalo SPC, Piccolo MC, Rodriguez LCE (2015) Estoque de carbono na biomassa aérea florestal em plantações comerciais de Eucalyptus spp. Scientia Forestalis, 43(105): 135-146.

Sistema de Proteção da Amazônia (2009) Zoneamento climático do Estado do Pará. Centro Técnico e Operacional de Belém-Pará: SIPAM. 30 p.

Soares CPB, Leite HG, Görgens EB (2005) Equações para estimar o estoque de carbono no fuste de árvores individuais e em plantios comerciais de eucalipto. Revista Árvore, 29(5): 711-718. doi: 10.1590/S010067622005000500006

Soares CPB, Oliveira MLR de (2002) Equações para estimar a quantidade de carbono na parte aérea de árvores de eucalipto em Viçosa, Minas Gerais. Revista Árvore, 26(5): $533-539$. doi: $10.1590 /$ S010067622002000500002

Vieira SA, Alves LF, Aidar MPM, Araújo LS, Baker T, Batista JLF, Campos MCR, Camargo PB, Chave J, Delitti WB, Higuchi N, Honório E, Joly CA, Keller M, Martinelli LA, Mattos EA, Metzker T, Phillips O, Santos FAM, Shimabukuro MT, Silveira M, Trumbore SE (2008) Estimation of biomass and carbon stocks: the case of the Atlantic Forest. Biota Neotropica, 8(2). doi: 10.1590/S1676-06032008000200001

Viera M, Bonacina DM, Schumacher MV, Calil FN, Caldeira MVW, Watzlawick LF (2012) Biomassa e nutrientes em povoamento de Eucalyptus urograndis na Serra do Sudeste-RS. Semina: Ciências Agrárias, 33: 2481-2490. doi: 10.5433/16790359.2012v33n6Supl1p2481 